\title{
AN ADAPTIVE APPROACH TO IMPLEMENTING INNOVATIVE URBAN TRANSPORT SOLUTIONS
}

\author{
Vincent Marchau, Warren Walker, and Ron van Duin \\ Delft University of Technology, The Netherlands, P.O. Box 5015, 2600 GA Delft \\ *vincentm@tudelft.nl
}

\begin{abstract}
Urban transport is facing an increasing number of problems. Innovative technological solutions have been proposed for many of these problems. The implementation of these solutions, however, is surrounded by many uncertainties on - for example, about future relevant developments for urban transport demand and supply, the possible consequences of these developments for urban transportation system performance, and the way crucial stakeholders will value these consequences. In order to deal with these uncertainties, a flexible or adaptive policy is proposed that takes some actions right away and creates a framework for future actions that allow for adaptations over time as knowledge about urban transport technologies accumulates and critical events with respect to the implementation of these technologies take place. The adaptive approach is illustrated for three promising technological solutions for urban transport problems: (1) Intelligent Speed Adaptation, (2) Personal Intelligent Travel Assistant, and (3) Underground Freight Transport.
\end{abstract}

\section{Introduction}

Increasing urbanization, lifestyle changes, decentralization of activities, and growing use of the private car, together with inadequate public transport services, have placed the mobility of persons and transportation of goods under pressure in many cities. For instance, urban congestion causes more air and noise pollution, short trips made with a cold engine increase fuel consumption exponentially, and emissions become three or four times higher while traffic speed is three or four times slower. In terms of safety, half of all fatal accidents take place in urban surroundings, and the highest casualties are among pedestrians, cyclists, and motorcyclists (CEC, 2001).

Various urban transport policies have been implemented in the past, including new infrastructures, park and ride facilities, improved public transport, road pricing, timeframes for goods delivery, etc (CEMT, 2006). Although useful, additional measures are required in order to (further) improve urban transport performance. Recently, several radical, innovative solutions have been proposed for dealing with these problems, such as intelligent vehicles, advanced travel information systems, and automated freight transport. These solutions, however, have either not yet been tried, or have been tried only on a small scale. Reasons for this lack of progress include the fact that the implementation of innovations in urban transport is surrounded by massive uncertainties regarding external developments relevant for urban transport (e.g. technological progress, economic developments, urban planning, demographic developments), the possible consequences of these developments for urban transportation system performance (e.g. impacts on throughput, safety, environment), and the way crucial

\footnotetext{
* Corresponding author
} 
stakeholders will value these consequences (e.g. changing preferences between vehicle throughput and environmental quality).

These uncertainties are often ignored or not handled well in traditional transport analyses that carry out modeling and impact assessments of innovative urban transport solutions -- e.g., by assuming that the future will be more or less the same as the present or by specifying a variety of scenarios, any one of which will occur with probability zero. Although useful, these approaches do not handle future trend breaks very well, such as technological breakthroughs, demographic and economic developments, shifts in activity behavior and related mobility, changing opinions on urban transport performance by crucial stakeholders, etc. As a result, decisionmaking with respect to innovative urban transport systems is avoided or becomes delayed (e.g. in order to perform more research or more pilot tests). And although uncertainty has attracted a great deal of interest in transport policy and planning since the $1990 \mathrm{~s}$, the ways it can or should be taken into account in policymaking are still developing (Van Geenhuizen et al., 2007).

In this paper, an adaptive policy approach is proposed, under which some actions are taken right away and a framework is created for future actions that allows for adaptations over time as knowledge about the performance and acceptance of innovative urban transport solutions accumulates and critical events for implementation take place. A systemic view on (transport) policymaking is presented in Section 2. In Section 3, the concept and set-up of an adaptive policy is given. The following three sections illustrate the adaptive approach for three specific urban transport solutions: intelligent speed adaptation (ISA), personal intelligent travel assistant (PITA), and underground freight transport (UFT). These illustrations show that, compared to traditional policymaking, the adaptive approach is highly promising in terms of handling the range of uncertainties related to implementing innovative urban transport solutions. Furthermore, they show that an adaptive approach enables policymakers to proceed with implementing these solutions despite the massive uncertainties surrounding them. The paper ends with conclusions and recommendations on further developing and implementing adaptive policies.

\section{A systemic view of policymaking for urban transport}

Policymaking on urban transport requires an integrated view with respect to the various alternative options, their possible consequences for the urban transport system performance, and societal conditions for implementation (Bertoloni et al., 2008). The basis for such a view has been provided by Walker (2000a). According to this view, policymaking, in essence, concerns making choices regarding a system in order to change the system outcomes in a desired way (see Figure 1). At the heart of this view is the system comprising the policy domain, in our case the urban transport system. An urban transport system can be defined by distinguishing its physical components (e.g. loads, vehicles, and infrastructure) and their mutual interactions. The results of these interactions (the system outputs) are called outcomes of interest and refer to the characteristics of the system that are considered relevant criteria for the evaluation of policies. The valuation of outcomes refers to the (relative) importance given to the outcomes by crucial stakeholders, including policymakers. Two types of forces act on

the system: external forces and policies. Both types of forces are developments outside the system that can affect the structure of the system (and, hence, the outcomes of 
interest to policymakers and other stakeholders). External forces refer to forces that are not controllable by the decisionmaker but may influence the system significantly, i.e. exogenous influences. A policy is a set of actions taken to control the system, to help solve problems within it or caused by it, or to help obtain benefits from it.

\section{<Figure 1 about here>}

Applying this analytical framework to the implementation of innovative urban transport solutions shows the following uncertainties. First, the possible influence of external forces, including technology development, is uncertain. Although the importance of exogenous events for the development of urban transport innovations, like urban sprawl, dispersion of work centers, working flexibility, etc., has been argued, most studies assume that technological progress will drive the implementation process, neglecting the likely co-evolution of transport technology and society (e.g. Geels and Smit, 2000). Second, the outcomes from urban transport technology implementation are uncertain (e.g. Cohen et al., 2002; Gertz, 2002). The way technology implementation might affect urban transport system performance is currently unknown, since the key-relationships determining transport system performance from technology implementation are very uncertain. Current knowledge about performance is often restricted to evaluating the impacts of specific urban transport technologies under unrealistic assumptions - e.g. assuming optimal technological performance, users that accept and use technologies as intended, and optimal urban transport conditions. As such, figures on performance improvements from implementation of these technologies are hardly more than indicative. Finally, the valuation of the outcomes from technology implementation is uncertain. Different stakeholders have different opinions about what is most important in the outcomes from the urban transport system (e.g. the environment vs. the economy). This results in different, often conflicting, needs regarding urban transport policies. As such, the willingness of stakeholders to accept (or reject) the implementation of urban transport innovations is uncertain.

Summarizing, large uncertainties exist about external developments, the outcomes of policy decisions on urban transport innovations, and the valuation of the outcomes by stakeholders involved in or affected by policy decisions (e.g. May et al., 2003). Up until now, policymakers have dealt with these uncertainties in one of two ways (Walker, $2000 \mathrm{~b}$ ). The most common approach is to pay little attention to them, assuming that the future world will be more or less the same as the current world. While this may be the easiest option for the short term, it means in fact accepting large uncertainty with respect to, for instance, policy outcomes. This could lead to a serious policy failure. For instance, in the Netherlands, Personal Rapid Transit (PRT) was once considered as a promising option to improve urban accessibility. PRT involves an automated, driverless taxi with a dedicated infrastructure, enabling significant higher average travel speeds then conventional public transport. The implementation of PRT in a Dutch city was abandoned because of unforeseen changes, both in policy priorities and key stakeholders, which had not been taken into account in advance (Van Zuylen and Ouwehand, 2005).

The second approach to dealing with these uncertainties is more enlightened. It assumes that the range of future worlds can be specified well enough to determine robust policies that will produce favorable outcomes in most of them. These future worlds are described by means of scenarios. The best policy is the policy that produces the most 
desirable outcomes across the range of scenarios. Although this approach has been successful in the past, the problem is that if the range of assumptions about the future turns out to be wrong, the negative consequences might be larger than if the uncertainties were totally ignored. In this rapidly changing world, is it feasible to develop and analyze a full set of plausible, future scenarios? Also, recent research points out that scenarios, in general, have rarely been used to address discontinuities in future developments; there has been a natural tendency for scenarios to stay close to evolutionary (discontinuity averse) business-as-usual situations (Van Notten et al., 2005).

Hence, traditional approaches have serious shortcomings in handling uncertainties regarding policymaking on urban transport innovations in an appropriate way (Dewar and Wachs, 2006). The challenge for enlightened policymaking is to develop other, innovative approaches to handle these uncertainties. Instead of focusing on the identification of all feasible urban transport technologies and development paths, which would be a waste of resources, an approach is needed that allows implementation to begin in the short term, adapts to the future course of events, and fully exploits knowledge that becomes available as time proceeds.

\section{The adaptive approach}

The first ideas on adaptive policies came early in the 1900s. Dewey (1927) put forth an argument proposing that 'policies be treated as experiments, with the aim of promoting continual learning and adaptation in response to experience over time'. A large literature review, however, has revealed that since that time there has been little literature relating directly to the topic of adaptive policies (IISD, 2006). In general, an adaptive approach allows implementation to begin prior to the resolution of all major uncertainties, with the policy being adapted over time based on new knowledge (Walker et al., 2001). It is a way that makes it possible to proceed with implementation of urban transport innovations despite the uncertainties. The approach makes adaptation explicit at the outset of policy formulation. Thus, the inevitable policy changes become part of a larger, recognized process and are not forced to be made repeatedly on an ad-hoc basis. Adaptive policies are devised not to be optimal for a best estimate future (which almost certainly will not occur), but to be robust across a range of plausible futures. Such policies combine actions that are time urgent with those that make important commitments to shape the future, preserve needed flexibility for the future, and protect the policy from failure. Under this approach, significant changes in the surface transportation system would be based on a policy analytic effort that first identifies system goals, and then identifies policies designed to achieve those goals and ways of modifying those policies as conditions change. Within the adaptive policy framework, individual actors would carry out their activities as they would under normal policy conditions. But policymakers, through monitoring and mid-course corrections, would try to keep the system headed toward the original goals. Figure 2 illustrates the adaptive policymaking process. In particular, the following steps summarize the process for creating and implementing an adaptive policy.

Both the first and the second steps are basically the same steps as are used currently in policy formulation. The first step constitutes the stage-setting step in the policymaking process. This step involves the specification of objectives, constraints, and available policy options. This specification should lead to a definition of success, i.e. the 
specification of desirable outcomes. In the next step, a basic policy is assembled, consisting of (a) the specification of an initial basic policy and (b) the identification of the conditions needed for the basic policy to succeed.

\section{<Figure 2 about here>}

In the third step of the adaptive policymaking process, the rest of the policy is specified. These are the pieces that make the policy adaptive. This step is based on identifying in advance the vulnerabilities of the basic policy (the conditions or events that could make the policy fail), and specifying actions to be taken in anticipation or in response to them. This step involves (a) the identification of the vulnerabilities, (b) defining actions to be taken immediately or in the future, and (c) defining signposts that should be monitored in order to be sure that the underlying analyses remain valid, that implementation is proceeding well, and that any needed policy interventions are taken in a timely and effective manner. Vulnerabilities are possible developments that can reduce the performance of a policy to a point where the policy is no longer successful. Actions are defined related to the type of vulnerability and when the action should be taken. Both certain and uncertain vulnerabilities can be distinguished. Certain vulnerabilities can be addressed by implementing mitigating actions -- actions taken in advance to reduce the certain adverse effects of a policy. Uncertain vulnerabilities are handled by implementing hedging actions -- actions taken in advance to reduce or spread the risk of possible adverse effects of a policy. For possible future actions, signposts are defined and a monitoring system established to determine when actions are needed to guarantee the progress and success of the policy. In particular, critical values of signpost variables (triggers) are specified, beyond which actions should be implemented to ensure that a policy progresses in the right direction and at a proper speed.

Once the above policy is agreed upon, the final step involves implementation. In this step, the actions to be taken immediately are implemented, signpost information related to the triggers begins to be collected, and policy actions are started, altered, stopped, or extended. After implementation of the initial actions, the adaptive policymaking process is suspended until a trigger event is reached. As long as the original policy objectives and constraints remain in place, the responses to a trigger event have a defensive or corrective character - that is, they are adjustments to the basic policy that preserve its benefits or meet outside challenges. Under some circumstances, neither defensive nor corrective actions will be sufficient. In that case, the entire policy will have to be reassessed and substantially changed or even abandoned. If so, however, the next policy deliberations would benefit from the previous experiences. The knowledge gathered in the initial adaptive policymaking process on outcomes, objectives, measures, preferences of stakeholders, etc., would be available and would accelerate the new policymaking process.

The adaptive policymaking approach seems promising for urban transportation system development in terms of how, in the face of deep uncertainty, policymaking can occur. In the following sections the concept of adaptive policymaking described above will be illustrated for developing three innovative transport policies regarding urban transport. 


\section{Case study 1: An Adaptive Policy for Implementing ISA}

A major objective for transport policies is the improvement of road traffic safety. In general, speed is a major factor contributing to road accidents. In addition to traditional measures (e.g. building separate infrastructure for slow and fast traffic, implementing roundabouts/traffic lights at junctions, driver-education campaigns, and legislation), a traffic safety policy strategy could include the implementation of ISA. ISA involves an in-vehicle device, using digital maps and GPS, that warns the driver and/or temporarily controls the vehicle in case of speeding. In Step 1 of the adaptive policy process, the constraints could be those imposed by costs, vehicle-throughput, travel time, comfort, convenience, etc. The definition of success involves, for instance, achieving a certain reduction of fatalities and injuries. For instance, test results in the Netherlands on ISA indicate a potential $34 \%$ reduction in fatal accidents and a $27 \%$ reduction in injuries as a result of large scale implementation of ISA on 30 and $50 \mathrm{~km} / \mathrm{h}$ roads, assuming that $60 \%$ of the vehicles are equipped with ISA (Wilmink et al., 2004). Research has shown that use of ISA on all roads might even reduce injury accidents up to $36 \%$ and fatal accidents by $59 \%$ (Carsten and Tate, 2005).

In Step 2, a basic policy needs to be assembled. Based on existing research, a promising basic policy might be to implement ISA for 'unsafe' drivers on 'unsafe roads'. Based on Dutch traffic safety statistics, such a basic policy would implement ISA for novice drivers on urban roads (Vlakveld, 2005). Due to expected driver acceptance problems, we initially choose to implement a type of ISA that only warns the driver in case of speeding and can be switched off and on by the driver. Necessary conditions for success of this basic policy include full availability of accurate speed limit data and reliable communication systems, driver and stakeholder acceptance, that drivers follow the system advice, and that adverse behavior (e.g. pay less attention to driving speed) does not occur.

In Step 3, the vulnerabilities of this basic policy are identified and the necessary conditions for success are translated into signposts that provide warnings in case of undesirable developments (see Table 1). For instance, a certain vulnerability of the new policy might be a lack of accurate speed limit data about incidental speed limits (work zones, accidents, etc.) or reliable communication at urban locations where there is lack of GPS signals. A mitigating action in such situations would be to build in some redundancy by providing temporary vehicle-roadway communication around incidents; in the second case, redundancy could be provided by installing beacons that would communicate within built-up areas. An uncertain vulnerability involves the adverse driving behavior that speed adaptation devices might induce. Experimental results indicate that, with speed adaptation devices implemented, drivers exhibit riskier gapacceptance, loss of vigilance, increased frustration, and increased impatience (Brookhuis et al., 2001). Therefore, the driving behavior of drivers with ISA should be monitored closely. 'Triggers' should be defined that would implement corrective policy actions when certain predefined levels of risky driving behavior develop. Another uncertain vulnerability involves driver acceptance. Driver education programs that educate drivers on the potential and the risks of ISA might be undertaken to hedge against this vulnerability. In addition, a signpost that monitors driver acceptance can be defined together with a trigger related, for instance, to an ISA penetration level required to reach the stated decrease in fatalities and injuries. 
Table 1: Dealing with vulnerabilities of the basic ISA policy

\begin{tabular}{|c|c|c|}
\hline Vulnerabilities & $\begin{array}{c}\text { Mitigating/Hedging } \\
\text { Actions }\end{array}$ & $\begin{array}{c}\text { Possible Signposts/ } \\
\text { Triggers/Actions }\end{array}$ \\
\hline $\begin{array}{l}\text { Certain: } \\
\text { Lack of accurate speed } \\
\text { limit data about } \\
\text { incidental speed } \\
\text { limits/within built-up } \\
\text { areas }\end{array}$ & $\begin{array}{l}\text { Mitigating Actions: } \\
\text { Provide temporary } \\
\text { vehicle-roadway } \\
\text { communication around } \\
\text { incidents/ within built-up } \\
\text { areas }\end{array}$ & \\
\hline $\begin{array}{l}\text { Uncertain: } \\
\text { Acceptance among } \\
\text { crucial stakeholders } \\
\text { (e.g. automotive } \\
\text { industry, insurance } \\
\text { companies) }\end{array}$ & $\begin{array}{l}\text { Hedging Actions: } \\
\text { - Spread investment/ } \\
\text { revenue risks among } \\
\text { public and private } \\
\text { parties } \\
\text { - Prespecify liability in } \\
\text { case of ISA incidents }\end{array}$ & \\
\hline $\begin{array}{l}\text { Uncertain: Driver } \\
\text { acceptance }\end{array}$ & $\begin{array}{l}\text { Hedging Actions: } \\
\text { - Educate drivers on the } \\
\text { potential and the risks } \\
\text { of ISA } \\
\text { - Provide financial } \\
\text { incentives to ISA } \\
\text { acceptance }\end{array}$ & $\begin{array}{l}\text { Monitor driver acceptance. In } \\
\text { case of e.g. too low ISA } \\
\text { penetration for reaching the } \\
\text { stated decrease in fatalities and } \\
\text { injuries, undertake corrective } \\
\text { actions (e.g. adapt basic policy } \\
\text { to reach goals). }\end{array}$ \\
\hline $\begin{array}{l}\text { Uncertain: } \\
\text { Adverse driving } \\
\text { behavior with ISA }\end{array}$ & $\begin{array}{l}\text { Hedging Actions: } \\
\text { - Let novice drivers } \\
\text { experience the } \\
\text { limitations of ISA } \\
\text { during a driving } \\
\text { education program. }\end{array}$ & $\begin{array}{l}\text { Monitor drivers with ISA. In } \\
\text { case of a certain level of riskier } \\
\text { driving behavior (trigger), } \\
\text { undertake corrective policy } \\
\text { actions (e.g. adapt ISA system } \\
\text { operating characteristics) }\end{array}$ \\
\hline
\end{tabular}

After agreeing upon the basic policy, conditions for success, policy actions, signposts, and trigger levels, the policy would be implemented. In case of a trigger event, the basic policy would be adjusted. For instance, in case the predefined levels of risky driving behavior are reached, corrective actions might be undertaken. These could include the exclusion of 'unsafe' drivers from the identified roads, or the vehicles of the unsafe drivers could be equipped with black-boxes in which real-time vehicle driving data would be stored. However, for some trigger events, neither defensive nor corrective actions might be sufficient. In a malfunctioning technology case, resulting in a large accident, the entire policy might come under serious pressure. If so, however, the policymaking process would not have to start all over again. The experiences gained and knowledge gathered in the initial adaptive policymaking process would be available and would accelerate the new policymaking process.

\section{Case study 2: An Adaptive Policy for Implementing Personal Intelligent Travel Assistant (PITA)}

Another major objective for transport policies is the efficient use by travelers of the existing transport capacity. Although travel information through radio, television, Internet, etc., is widely available, its effectiveness is low, since (Chorus et al., 2006): 
- Current information is limited (e.g. often no alternative routes are offered for travelers confronted with congestion);

- Current information is unimodal (i.e. no alternative modes are offered for travelers confronted with delays);

- Current information is generic (i.e. the specific travel preferences of individual travelers are not taken into account).

Therefore, a mobile-phone based travel information service has been developed that provides travelers with a full overview of travel options for traveling in the most efficient and effective way from a certain origin to a certain destination. This so-called Personal Intelligent Travel Assistant (PITA) is expected to become available within the next few years (TRAIL Research School, 2002). In Step 1 of developing an adaptive policy, important constraints would be financial and a requirement that other transport policy objectives (e.g. safety, environmental stress) not increase due to the implementation of PITA. A definition of success might be a specified improvement in the (reliability of) travel times. For instance, national policy objectives in the Netherlands include that, in $2020,95 \%$ of all movements by road should be on time during the rush hour, and $90 \%$ of the trains should be on time (Ministry of Transport, Public Works and Water Management, 2000).

In Step 2, a basic policy might be to implement PITA first for those individuals who have a high value of time, e.g. professional drivers and business travelers (e.g. Polydoropoulou. and Ben-Akiva, 1999; Bovy, 2001). These travelers are likely to be the most willing to adopt PITA since, by definition, they are the subgroup of travelers that are most affected by travel time losses and unreliability. Basic conditions for success include the willingness of key actors (e.g. road traffic managers, public transport operators) to provide reliable and accurate travel information, the availability of integrated models to combine multimodal travel data to meet individual preferences, and the willingness of professional drivers and business travelers to buy and use PITA.

In Step 3, the several vulnerabilities of this basic policy are identified. A certain vulnerability might be a temporary lack of travel data availability for certain modes. A mitigating action might to include a back-up travel information system that travelers can use in case of a temporary black-out. Another certain vulnerability would be that travelers resist the willingness to buy PITA because it affects their privacy - i.e. it seems like 'Big Brother' watching their travel behavior. Some travel-data encoding that avoids personal identification in relation to travel choices can be used to mitigate this vulnerability. An uncertain vulnerability involves the user acceptance of PITA - in particular, whether the PITA advice will be followed by travelers (Bonsall, 2004). A signpost can be constructed that monitors the level of PITA use. As soon as the level of use drops under a predefined level (trigger), some corrective action might be initiated, such as advertising or educating travelers on the advantages of using PITA when traveling. This is related to another uncertain vulnerability: the willingness of key actors to cooperate on implementing PITA due to, for instance, too large investment risks for public transport operators. A hedging action might be that, at the beginning, public policymakers give some insurance for companies against potential investment losses. 
Table 2: Dealing with vulnerabilities of the basic PITA policy

\begin{tabular}{|l|l|l|}
\hline \multicolumn{1}{|c|}{ Vulnerabilities } & \multicolumn{1}{c|}{$\begin{array}{c}\text { Mitigating/Hedging } \\
\text { Actions }\end{array}$} & \multicolumn{1}{c|}{$\begin{array}{c}\text { Possible Signposts/ } \\
\text { Triggers/Actions }\end{array}$} \\
\hline $\begin{array}{l}\text { Certain: (Temporary) } \\
\text { lack of travel data } \\
\text { availability }\end{array}$ & $\begin{array}{l}\text { Mitigating Actions: } \\
\text { Provide back-up travel } \\
\text { information system }\end{array}$ & \\
\hline $\begin{array}{l}\text { Certain: Willingness of } \\
\text { travelers to buy PITA } \\
\text { due to e.g. privacy } \\
\text { reasons, individual cost } \\
\text { benefit trade-offs. }\end{array}$ & $\begin{array}{l}\text { Mitigating Actions: } \\
\text { Provide travel-data } \\
\text { encoding ensuring } \\
\text { privacy of travelers } \\
\text { Give (financial) } \\
\text { incentives to travelers } \\
\text { for buying PITA }\end{array}$ & \\
\hline $\begin{array}{l}\text { Uncertain: Willingness } \\
\text { of professional drivers } \\
\text { and business traveler to } \\
\text { use PITA }\end{array}$ & $\begin{array}{l}\text { Hedging Actions: } \\
\text { Explain advantages } \\
\text { of PITA use to target } \\
\text { groups }\end{array}$ & $\begin{array}{l}\text { Monitor the level of PITA use, } \\
\text { in case too low usage (trigger), } \\
\text { implement some corrective } \\
\text { action (e.g. provide incentives to } \\
\text { travelers for using PITA, expand } \\
\text { basic policy to other target } \\
\text { groups). }\end{array}$ \\
\hline $\begin{array}{l}\text { Uncertain: Willingness } \\
\text { of key actors to } \\
\text { cooperate on } \\
\text { implementing PITA }\end{array}$ & $\begin{array}{l}\text { Hedging Actions: } \\
\text { Provide insurance for } \\
\text { PITA companies } \\
\text { against potential } \\
\text { investment losses }\end{array}$ & \\
\hline
\end{tabular}

Once the above policy is agreed upon, the basic PITA policy is implemented and signpost information begins to be collected. In case of a trigger event, the pre-defined action is undertaken. If, for instance, the number of travelers following the PITA advice appears to be too low, some corrective action can be undertaken - e.g., giving some financial incentive to those travelers who do comply with the PITA advice. For some trigger events, only a full reassessment of the basic policy might be sufficient. In case some of the key actors are not willing to participate anymore, e.g., if the returns on investment remain too low, the entire policy might come under serious pressure. However, the knowledge gathered in the initial adaptive policymaking process on outcomes, objectives, measures, preferences of stakeholders, etc., would already be available and would accelerate the new policymaking process.

\section{Case study 3: An Adaptive Policy for Implementing Underground Freight Transport (UFT)}

In many cities, the distribution of consumer goods, office supplies, building materials, and the collection of waste and reverse products is of growing concern for city authorities, trucking companies, logistics service providers, retail chains, and city inhabitants. Goods movements are largely indifferent to the internal structure of cities, Urban policies targeted on freight mobility appear to be quite inefficient, and the improvement of urban logistic services is slow in emerging, despite growing needs (Dablanc, 2007). As mentioned in the White Paper of the European Commission (2001), 
a major policy objective is the development of sustainable urban goods transport, which means the facilitation of continuing economic growth by developing transport with high reliability and good accessibility, while protecting the environment and ensuring a better quality of life for future generations. For cities, this implies that reductions should be obtained in terms of truck operating costs, travel times, $\mathrm{CO}_{2}$ and $\mathrm{NO}_{\mathrm{x}}$ emissions, and traffic accidents. A definition of success in this case might be to achieve a reduction by a factor of twenty in transport related emissions, noise pollution, energy consumption, and use of space in the next fifty years, as suggested in the Brundlandt report (World Commission on Environment and Development, 1987).

For freight transport in urban areas, this implies a serious reduction (by 70\%) in freight movements (IPOT, 2000). Additional goals are to protect people in downtown areas, regulate the goods supply flow, prevent physical damage to inner cities, and create a good shopping environment. Among the traditional options for attempting to achieve these goals are speed limitation, loading and unloading zones, time windows (Van Duin, 2005), and the use of city distribution centers. So far, the traditional options have not been sufficient to achieve the goals, and the use of city distribution centers has not proven to be feasible, due to the low level of interest shown by carriers, who prefer direct deliveries (Van Duin, 1997). Thus, more radical solutions are needed. One such possibility is underground freight transport (UFT), which is viewed as the only possible and serious solution for sustainable freight transport (e.g. Zhang et al., 2005; Pielage and Rijsenbrij, 2006).

In Step 2 of the adaptive procedure, a basic policy for UFT is assembled. It would seem logical to start by implementing UFT in those urban regions where the traffic problems are most serious and there are large volumes of time-critical goods. Within the Netherlands, one such area is around Schiphol Airport. In fact, a pilot project, ULSASH (Underground Logistics System - Aalsmeer Schiphol Hoofddorp), was actually set up in that area in order to address the fact that deteriorating accessibility, increasing traffic congestion, and growing costs were threatening the economic position of the national airport and the flower auction market. The necessary conditions for success of such a UFT policy include a substantial demand for freight transport, sufficient funding, and technological reliability of the UFT system.

In Step 3, the vulnerabilities of this basic policy are identified. A certain vulnerability is not having enough transport demand, since most retailers will probably prefer to use their existing distribution structures instead of using UFT. Their willingness to participate is very much dependent on the operational costs and on the speed and reliability of delivery. Mitigating actions might include the provision of compensation in case of (too) low reliability and financial incentives for UFT use. In addition, authorities might increase the enforcement of their inner city regulations and increase urban delivery costs (e.g., using cordon fees in order to encourage the shift from conventional delivery by truck to the new UFT). A well known uncertain vulnerability for large infrastructure projects, including UFT, are cost overruns (Priemus et al., 2008). For example, in 1995 a pilot UFT project was implemented between the flower auction in Aalsmeer, the Amsterdam Airport, and a nearby rail terminal. Due to an overrun of costs for another large infrastructure project (the Betuwe Line), the reserved budget for the construction of the pilot case was used to cover the expenses of the Betuwe Line and the pilot UFT project was stopped. If this vulnerability had been taken into account, the pilot UFT project might have been successful. 
Table3: Dealing with vulnerabilities of the basic UFT policy

\begin{tabular}{|c|c|c|}
\hline Vulnerabilities & Mitigating/Hedging Actions & $\begin{array}{c}\text { Possible Signposts/ } \\
\text { Triggers/Actions }\end{array}$ \\
\hline $\begin{array}{l}\text { Certain: } \\
\text { Transport demand } \\
\text { for the UFT }\end{array}$ & $\begin{array}{l}\text { Mitigating Actions: } \\
\text { - Compensate UFT users for } \\
\text { potential losses } \\
\text { - Encourage UFT use and } \\
\text { discourage use of other } \\
\text { urban transport modes }\end{array}$ & \\
\hline $\begin{array}{l}\text { Uncertain: Cost } \\
\text { overruns for } \\
\text { building/operating } \\
\text { UFT }\end{array}$ & $\begin{array}{l}\text { Hedging Actions: } \\
\text { - Establish public-private } \\
\text { partnerships, enabling } \\
\text { private investments in } \\
\text { (parts of) constructing and } \\
\text { operating facilities } \\
\end{array}$ & $\begin{array}{l}\text { Monitor expenditures. In case } \\
\text { of cost overruns, implement } \\
\text { defensive (e.g. explain cause } \\
\text { to the public) or corrective } \\
\text { (e.g. adapt UFT to increase } \\
\text { revenues) actions }\end{array}$ \\
\hline $\begin{array}{l}\text { Uncertain: } \\
\text { Technological } \\
\text { reliability of UFT }\end{array}$ & $\begin{array}{l}\text { Hedging Actions: } \\
\text { - Provide insurance in case } \\
\text { of malfunctioning } \\
\text { technology } \\
\text { - Build in some } \\
\text { redundancy, by providing } \\
\text { short bypass connections } \\
\text { on crucial trunk lines }\end{array}$ & $\begin{array}{l}\text { Monitor vehicle status } \\
\text { information continuously with } \\
\text { pro-active RFID (Radio } \\
\text { Frequency IDentification) }\end{array}$ \\
\hline
\end{tabular}

Once the above policy is agreed upon, the basic UFT policy is implemented and signpost information begins to be collected. In case of a trigger event, the pre-defined action is undertaken. In fact, as a step towards implementation, many towns in the Netherlands had carried out feasibility studies of UFT (Versteegt et al., 2001). But, since then some local governments have reassessed their policy by changing their scope from Underground Freight Transport to Undisturbed Freight Transport with the development of dedicated freight lines operated by environmentally-friendly vehicles. Nonetheless, even though they have already adapted their policy, they can still benefit from the technical knowledge gained from the former pilot project ULS-ASH.

\section{Conclusions and discussion}

This paper has focused on handling the uncertainties surrounding the implementation of innovative urban transport solutions from the perspective of public policymaking. Several studies and pilot projects have shown that various technologies have great potential to contribute to urban transport policy goals. On the other hand, public policy and decisionmaking is confronted with the existence of large uncertainties related to the implementation of these technologies, which inhibits their implementation. The challenge for enlightened policymaking is to develop innovative approaches for handling these uncertainties. The paper has proposed an approach involving a flexible or adaptive policy that allows adaptations in time as experience and knowledge about the real-world functioning of urban transport technological innovations proceeds. In particular, policymakers are encouraged to first develop a normative view and then guide the policy development, implementation, and adaptation process based on gathering information that allows the resolution of the uncertainties over time. The adaptive policy approach was illustrated by three cases designed to achieve different 
urban transport policy objectives (an improvement of urban traffic safety, a more efficient use of different urban travel options, and improved urban freight transportation). We showed how policymakers can cope with uncertainties concerning urban transport technologies by implementing an adaptive policy, and how such a policy can be adjusted as new information becomes available on its real world performance. The illustrations have shown that, compared to traditional policymaking, the adaptive approach is highly promising in terms of handling the range of uncertainties related to urban transport technology implementation for traffic safety and efficiency. Future challenges in this field involve a further specification and testing of the adaptive approach focused on developing systematic approaches to fully identifying the vulnerabilities, specifying trigger events and trigger values, and laying the political and legal groundwork for implementing adaptive policies. One way of testing and assessing the attractiveness of the adaptive approach might be to use scenario and simulation gaming to compare the performance of the adaptive policymaking approach to more traditional policymaking approaches.

\section{References}

Bertolini, L., Le Clercq, F., Straatemeier, T. (2008) 'Urban Transportation Planning in Transition', Transport Policy 15(2), pp.69-72.

Bonsall, P. (2004) 'Traveller Behavior: Decision-Making in an Unpredictable World', Journal of Intelligent Transportation Systems: Technology, Planning, and Operations, 8(1), pp. 45-60.

Bovy, P., (2001) 'Traffic Flooding the Low Countries: How the Dutch Cope With Motorway Congestion', Transport Reviews, 21(1), pp.89-116.

Brookhuis, K.A., Waard, D. de, and Janssen,W.H (2001) 'Behavioural Impacts of Advanced Driver Assistance Systems - An Overview', European Journal of Transport and Infrastructure Research,1(3), pp. 245-253.

Carsten, O.M.J. and Tate, F.N. (2005) 'Intelligent Speed Adaptation: Accident Savings and Cost-Benefit Analysis', Accident Analysis \& Prevention, 37(3), pp. 407-416.

CEMT (European Conference of Ministers of Transport) (2006) 'Sustainable Urban Travel--Implementing Sustainable Urban Travel Policies: Applying the 2001 Key Messages', OECD, Paris.

Chorus, C.G., Molin, E.J.E., Wee, B. van (2006) 'Use and Effects of Advanced Traveller Information Services (ATIS): A Review of The Literature', Transport Reviews, 26(2), pp. 127-149.

Cohen, G., Salomon, I., and Nijkamp P. (2002) 'Information-Communications Technologies (ICT) and Transport: Does Knowledge Underpin Policy?', Telecommunications Policy, 26(1-2), pp. 31-52.

CEC - Commission of the European Communities (2001) 'European Transport Policy for 2020: Time to Decide', COM(2001)370, Office for Official Publications of the European Communities, Luxembourg. 
Dablanc, L. (2007) 'Goods Transport in Large European Cities: Difficult to Organize, Difficult to Modernize', Transportation Research A: Policy and Practice, 41(3), pp. 280-285.

Dewar, J.A. and Wachs, M. (2006) 'Transportation Planning, Climate Change, and Decisionmaking Under Uncertainty'. Proceedings of the Workshop Conference on Climate Change and U.S. Transportation, National Academies of Sciences and Engineering, Washington, D.C.

Dewey, J. (1927) The Public and its Problems, Holt and Company, New York.

European Commission (2001), European Transport policy for 2010: time to decide, $\operatorname{COM}(2001)$ 370, White Paper of the Commission of the European Communities, Brussels.http://europa.eu.int/comm/energy transport/library/lb texte complet en.pdf.

Geels, F., Smit, W.A. (2000) 'Failed technology futures: pitfalls and lessons from a historical survey', Futures, 32(9-10), pp. 867-885.

Gertz, C. (2002) 'The Relationship Between Transportation, Urban Form and ICT: What We Know, What We Don't Know'. Paper presented at the: STELLA Focus Group 2 Trends Meeting, Arlington, VA, USA, 17 January. (Available online at: http://www.stellaproject.org/focusgroup2/Washington/CarstenGertz.pdf)

IISD (International Institute for Sustainable Development) (2006) Designing Policies in a World of Uncertainty, Change and Surprise - Adaptive Policymaking for Agriculture and Water Resources in the Face of Climate Change - Phase I Research Report, IISD, Winnipeg.

IPOT (Interdepartementale Projectgroep Ondergronds Transport) (2000) 'Transport Under Us: From Vision to Realization', Final report, The Hague (In Dutch).

May, A.D., Jopson, A., and Mathews, B. (2003) 'Research Challenges in Urban Transport Policy', Transport Policy, 10 (3), pp. 157-164.

Ministry of Transport, Public Works and Water Management (2000) 'The National Traffic and Transport Plan', The Hague.

Pielage, B. -J. and Rijsenbrij, J. (2006) 'Developments in Underground Freight Transportation,' Chapter 5 in Konings, R., Priemus, H., and Nijkamp, P. (eds.), The Future of Automated Freight Transport: Concepts, Design and Implementation, Edward Elgar Publishing Ltd., Cheltenham.

Polydoropoulou, A. and Ben-Akiva, M. (1999) 'The Effect of Advanced Traveler Information Systems (ATIS) on Travelers' Behavior'. Behavioral and Network Impacts of Driver Information Systems, pp. 317-352.

Priemus, H.P., Flyvbjerg, B., and Van Wee, G.P. (eds.) (2008) Decisionmaking on Mega-projects: Cost-Benefit Analysis, Planning and Innovation, Edward Elgar Publishing Ltd., Cheltenham. 
TRAIL Research School (2002) 'Progress report Seamless Multimodal Mobility 19972001', TRAIL Research School, Delft.

Van Notten, Ph.W.F., Sleegers, A. M., Van Asselt M. B. A. (2005) 'The Future Shocks: On Discontinuity and Scenario Development', Technological Forecasting and Social Change, 72(2), pp. 175-194.

Van Duin J.H.R. (1997) 'Evaluation and Evolution of the City Distribution Concept', Urban Transport and the Environment for the 21st Century III, Computational Mechanics Publications, Wessex, pp 327-337.

Van Duin, J.H.R. (2005) 'Sustainable Urban Freight Policies in the Netherlands: A Survey', Sustainable Development and Planning II, Vol. 1, WIT Press, Southampton, pp 3-13.

Van Geenhuizen, M., Reggiani, A., and Rietveld, P. (2007) 'New Trends in Policymaking for Transport and Regional Network Integration', in Van Geenhuizen, M., Reggiani, A., and Rietveld, P. (eds.) Policy Analysis of Transport Networks, Ashgate, Aldershot, pp. 1-16.

Van Zuylen, H., and Ouwehand, A. (2005) 'Learning from a Failed Innovation Process - Personal Rapid Transit for a Dutch City', Transportation Research Records, No. 1930, pp. 91-98.

Versteegt, C., Verbraeck, A, Geerdes, S. (2001) 'Simulation as a Supporting Tool for the Multidisciplinary Design of Underground Freight Transport Systems', Second International Conference on City Logistics, Okinawa, Japan.

Vlakveld, W.P. (2005) 'Young, Novice Motorists, Their Crash Rates, and Measures to Reduce Them; a Literature Study', R2005-3, SWOV, Leidschendam.

Walker, W.E. (2000a) 'Policy Analysis: A Systematic Approach to Supporting Policymaking in the Public Sector', Journal of Multi-Criteria Decision Analysis, 9(1-3), pp. 11-27.

Walker, W.E. (2000b) Uncertainty: The Challenge for Policy Analysis in the 21st Century, Inaugural Speech, Delft University Press, Delft.

Walker, W.E., Rahman, S.A., and Cave, J. (2001) 'Adaptive Policies, Policy Analysis, and Policymaking', European Journal of Operational Research, 128(2), pp. 282-289.

Wilmink, I., Versteegt, E., Liu, R., and Hegeman, G. (2004) 'Network Effects and Policy Impacts of ISA - A Micro Simulation Analysis', Proceedings of the $11^{\text {th }}$ ITS World Congress (Nagoya, 18-24 October, 2004), VERTIS, Tokyo.

World Commission on Environment and Development (1987) 'Our Common Future', Oxford University Press, Oxford, UK.

Zhang, M.-J.a, Qian, Q.-H.b, Tang, J.c (2005) 'Current Status and Anticipated Future Use of Modern Underground Freight Transport Systems', Journal of Beijng University 
of Technology, 31(6), pp. 580-584. 
Figure 1 - An integrated view of policymaking. Figure 2 - The adaptive policymaking procedure. 
Figure 1:

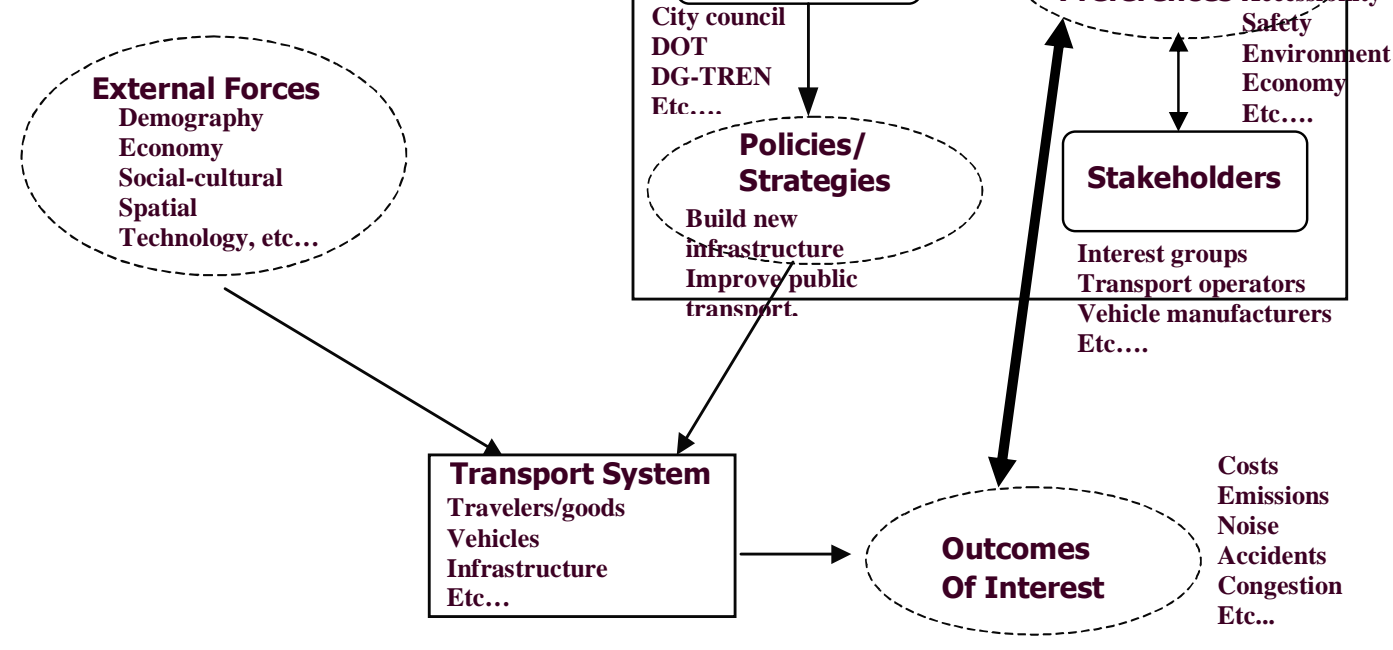


Figure 2:

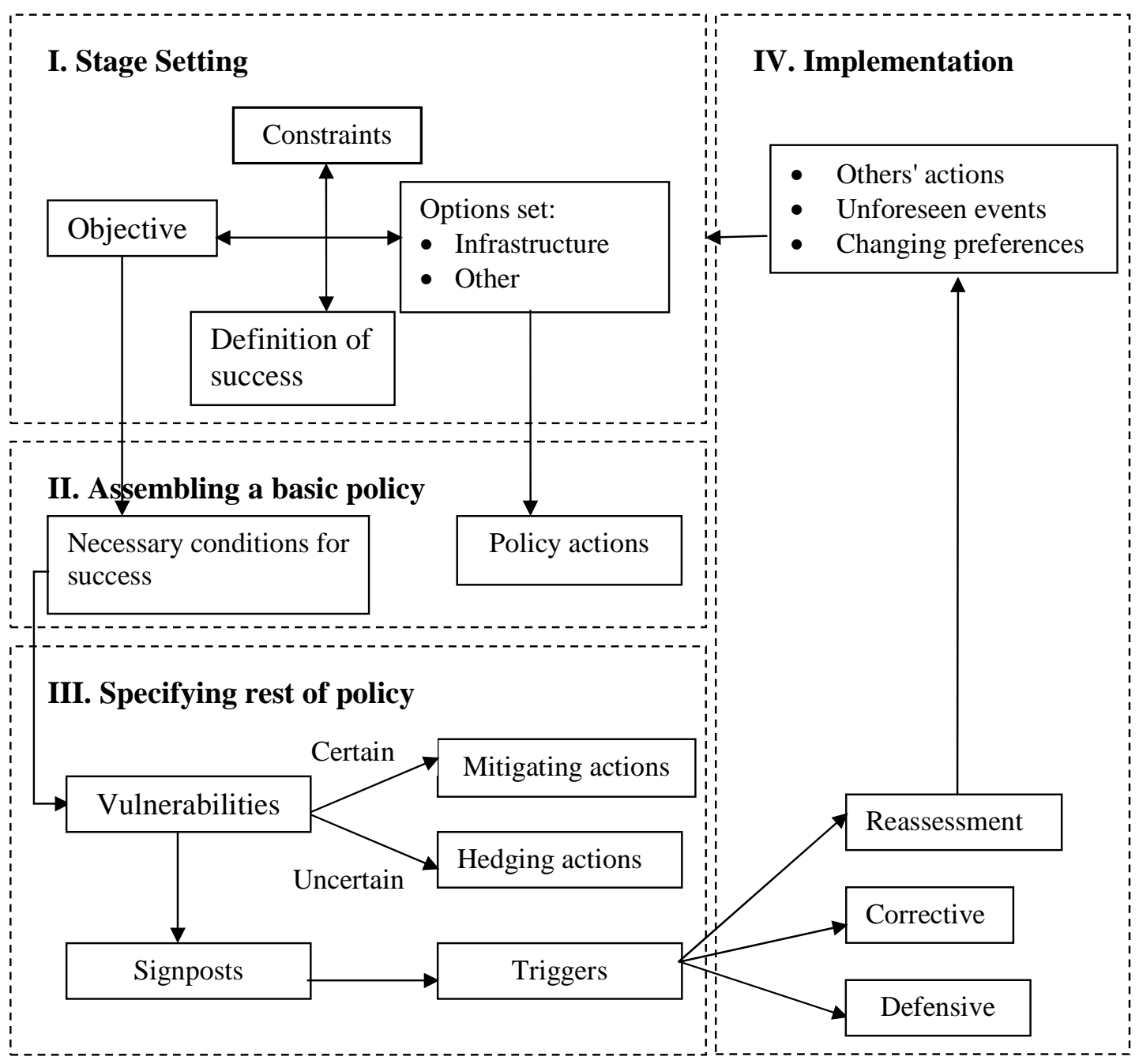

